\title{
PENDAMPINGAN PEMASARAN ONLINE DI UD MADANI MAKMUR SIDOARJO
}

\section{TRAINING AND MENTORING ABOUT ONLINE MARKETING AT UD MADANI MAKMUR SIDOARJO}

\author{
Khoirul Ngibad $^{1)}$, Nambi Sembilü ${ }^{2)}$, Setiawan ${ }^{3)}$, Intan Syahrani Putri ${ }^{4)}$ \\ ${ }^{1}$ Fakultas Ilmu Kesehatan, Universitas Maarif Hasyim Latif Sidoarjo \\ ${ }^{2,4}$ Fakultas Teknik, Universitas Maarif Hasyim Latif Sidoarjo \\ ${ }^{3}$ Fakultas Ekonomi dan Bisnis, Universitas Maarif Hasyim Latif Sidoarjo \\ ${ }^{1}$ Email: khoirul_ngibad@dosen.umaha.ac.id
}

\begin{abstract}
Abstrak: Dalam Program Kemitraan Masyarakat ini, kami memilih 1 mitra ekonomi produktif dalam pembuatan sirup herbal (kunyit asem, jahe merah, dan lemon sereh). Permasalahan mitra Program Kemitraan Masyarakat dalam aspek pemasaran adalah mitra belum mengerti cara pemasaran menggunakan digital marketing agar produk mitra dapat dipasarkan secara online ke seluruh wilayah di Indonesia. Tujuan Program Kemitraan Masyarakat ini adalah untuk mengatasi permasalahan prioritas yang sedang dihadapi mitra Program Kemitraan Masyarakat dalam aspek pemasaran adalah memberikan pelatihan dan pendampingan dalam pemasaran produk secara online melalui pembuatan dan pengelolaan website, penggunaan Google AdWords, serta pembuatan dan pengelolaan toko online di Shopee. Kegiatan pengabdian masyarakat ini dilakukan dengan cara penyampaian informasi tentang pentingnya penggunaan digital marketing dalam aspek pemasaran. Kemudian, tim pengabdian masyarakat memberikan pelatihan dan pendampingan tentang penggunaan website, Google AdWords, serta pembuatan dan pengelolaan toko online di Shopee. Hasil yang diperoleh dalam Program Kemitraan Masyarakat ini adalah mitra mempunyai website (http://www.sirupherbalmadani.com) dan mampu mengelolanya untuk pemasaran online, mitra mampu mengaplikasikan Google Adwords untuk iklan berbayar, serta mitra mempunyai toko online di Shopee (https://shopee.co.id/madani_makmur) dan mampu mengelolanya untuk memaksimalkan pemasaran online.
\end{abstract}

Kata Kunci: Pemasaran online, Program kemitraan masyarakat, Sirup herbal

ABSTRACT: In this Community Partnership Program, we choose 1 productive economic partner in manufacture of herbal syrup (turmeric tamarind, red ginger,and lemon lemongrass). The problem with Community Partnership Program partners in the marketing aspect is that partners do not understand how to market using digital marketing in order to partner products can be marketed online to all regions in Indonesia. The purpose of this Community Partnership Program is to overcome the priority problems that are being faced by Community 
Partnership Program partners in the marketing aspect, namely providing training and assistance in online product marketing through the creation and management of website, the use of Google AdWords, and the creation and management of an online store at Shopee. This community service activity is carried out by delivering information about the importance of using digital marketing in the marketing aspect. Then, the community service team provides training and assistance on the use of websites, Google AdWords, and the creation and management of online stores at Shopee. The results obtained in this Community Partnership Program are partners have website (http://www.sirupherbalmadani.com) and capable to manage it for online marketing, partners are able to apply Google Adwords for paid advertising, and partners have an online store at Shopee (https://shopee.co.id/madani_makmur) and competent to manage it to maximize online marketing.

Keywords: Community partnership program, Herbal syrup, Online marketing

\section{PENDAHULUAN}

Berdasarkan hasil observasi di Desa Sidokerto Kecamatan Buduran Kabupaten Sidoarjo terdapat UMKM (Usaha Mikro Kecil Menegah) yang bergerak dalam pembuatan sirup herbal. Dalam program PKM (Program Kemitraan Masyarakat) ini, kami memilih 1 (satu) mitra usaha yang merupakan masyarakat yang produktif secara ekonomi. Tim PKM melakukan wawancara dan mencari permasalahan priorotas mitra untuk segera dicarikan solusi. Profil mitra usaha tersebut adalah:

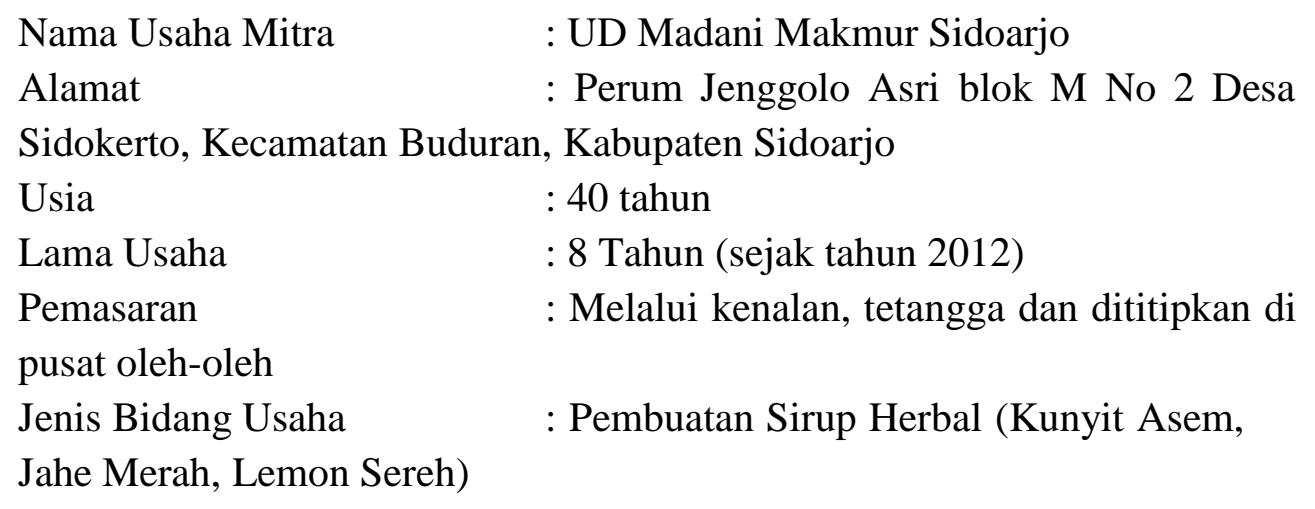

Produk sirup herbal mitra sudah memuat informasi tentang nama produk, komposisi, masa kadaluarsa, izin depkes atau instansi terkait (P-IRT), pembuat produk, dan volume produk. Pengemasan produk sudah menggunakan botol plastik yang bersih dan sudah terdapat label produk. Strategi pemasaran mitra 


\section{INTEGRITAS : Jurnal Pengabdian}

Vol 5 No 2 Desember 2021

ISSN 2580 - 7978 (cetak) ISSN 2615 - 0794 (online)

sampai saat ini adalah hanya mengandalkan pemasaran secara offline. Harga jual produk sirup herbal mitra adalah Rp 25.000,00 per botol ukuran $500 \mathrm{~mL}$. Semua varian produk dijual dengan harga sama, padahal ada produk yang dari aspek biaya produksi lebih mahal. Mitra menitipkan produknya di outlet-outlet dan pusat oleh-oleh dengan sistem konsinyasi yang sampai saat ini sudah mencapai 30 outlet. Area pemasaran mitra masih sebatas di Sidoarjo, Surabaya dan Pasuruan. Mitra juga memasarkan produknya melalui reseller yang merupakan tetangga, kenalan, teman dekat, dan kerabat. Biasanya reseller mitra membawa produk sirup herbal sebanyak kurang lebih 20 botol. Rata-rata reseller membutuhkan waktu kurang lebih 2 minggu untuk bisa menjual seluruh produk sirup herbal yang dibawanya. Setelah semua produk laku terjual, reseller baru menyetorkan ke mitra. Akan tetapi, permintaan sirup herbal dari para pelanggan mulai mengalami penurunan pada awal bulan Agustus 2020 yang disebabkan oleh menurunnya daya beli masyarakat karena terdampak Covid-19. Hal tersebut mengakibatkan pendapatan mitra mengalami penurunan sebesar 50\% dari pendapatan biasanya.

Adapun pemasaran secara online (internet) yang dilakukan mitra hanya sebatas menggunakan media sosial instagram dan itupun masih belum maksimal. Gambar 1 menunjukkan tampilan akun Instagram yang digunakan untuk pemasaran secara online. Sampai saat ini, akun Instagram mitra hanya memuat 2 postingan dengan hanya sebanyak 25 followers. Berdasarkan hasil wawancara dengan tim PKM mitra menyampaikan bahwasanya tidak mengetahui teknik pemasaran secara online. Mitra sangat menginginkan usahanya bisa dipasarkan secara online, misalnya dengan penggunaan website untuk penjualan produk. Selain itu, mitra membutuhkan bantuan untuk diajari cara menggunakan website atau digital marketing untuk pemasaran online agar penjualan bisa meningkat [4] [5]. 


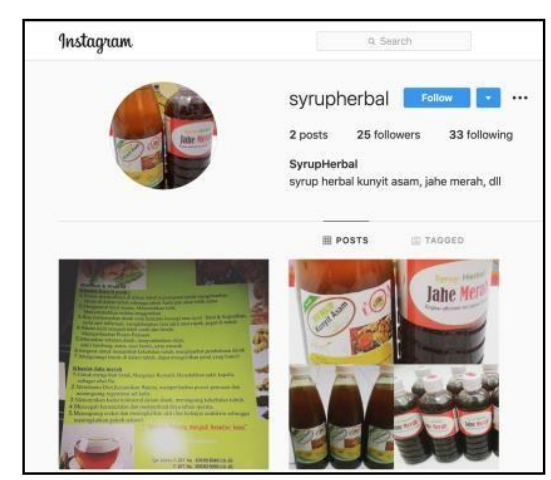

Gambar 1. Tampilan akun Instagram mitra yang digunakan untuk pemasaran online

Berdasarkan hasil observasi dan diskusi baik secara langsung dengan datang ke rumah mitra maupun secara online menggunakan whatsapp terdapat beberapa masalah yang dihadapi dari aspek pemasaran yang harus segera diselesaikan guna peningkatan pemberdayaan mitra, yang meliputi: peningkatan pengetahuan, peningkatan keterampilan, peningkatan jumlah omset mitra, dan peningkatan pendapatan/keuntungan mitra.

\section{METODE}

Kegiatan pengabdian masyarakat dengan tema "Pendampingan Pemasaran Online di UD Madani Makmur Sidoarjo" dilaksanakan di UMKM pembuatan sirup herbal yang beralamat di Perum Jenggolo Asri blok M No 2 Desa Sidokerto, Kecamatan Buduran, Kabupaten Sidoarjo. Pelaksanaan kegiatan pengabdian masyarakat ini meliputi beberapa tahapan diantaranya yaitu :

\section{Tahap 1. Analisis Situasi dan Kesepakatan Persoalan Prioritas Mitra}

Tim pengabdian masyarakat telah melakukan wawancara yang bertujuan untuk mengetahui profil mitra dan mendata permasalahan-permasalahan yang sedang dihadapi mitra dari askpek pemasaran.

\section{Tahap 2. Persiapan}

Pada tahap, tim pengabdian masyarakat telah mempersiapkan segala kebutuhan dalam proses pelaksanaan kegiatan pengabdian masyarakat di lokasi mitra. Persiapan yang telah dilaksanakan meliputi:

1. Pembuatan materi dalam bentuk modul dan indikator-indikator penilaian ketrampilan untuk kegiatan pelatihan dan pendampingan di lokasi mitra. 
INTEGRITAS : Jurnal Pengabdian

Vol 5 No 2 Desember 2021

ISSN 2580 - 7978 (cetak) ISSN 2615 - 0794 (online)

2. Pembuatan materi untuk kegiatan pelatihan pemasaran online menggunakan Shopee.

3. Pembuatan website untuk penjualan sirup herbal secara online.

4. Pembuatan akun dashboard Google AdWords.

\section{Tahap 3. Pelaksanaan}

Pelatihan dan pendampingan dalam pemasaran produk sirup herbal secara online dimulai dengan penyampaian informasi tentang pentingnya penggunaan digital marketing dalam aspek pemasaran. Dalam kegiatan ini, tim pengabdian masyarakat akan memberikan website, akun dashboard Google AdWords, dan akun shopee kepada mitra. Kemudian, tim pengabdian masyarakat memberikan pelatihan dan pendampingan tentang penggunaan website, Google AdWords, dan media sosial agar mitra mampu secara mandiri mengelola pemasaran menggunakan internet marketing. Dalam kegiatan ini, tim pengabdian masyarakat menggunakan materi dalam bentuk modul dan power point agar materi dapat mudah dipraktikkan oleh mitra. Kegiatan ini diharapkan mampu meningkatkan jumlah produk sirup herbal yang terjual ke seluruh wilayah Indonesia sehingga dapat meningkatkan pendapatan dan omset mitra. Baik sebelum dan sesudah pelatihan dan pendampingan, dilakukan penilaian tentang ketrampilan mitra dalam penggunaan media online untuk pemasaran. Kemudian, pelaksanaan kegiatan juga didokumentasikan baik dal am bentuk foto maupun video.

\section{Tahap 4. Monitoring dan Evaluasi Kegiatan Pengabdian Masyarakat}

Dalam kegiatan ini, tim pengabdian masyarakat melakukan monitoring dan evaluasi terhadap keberlanjutan kegiatan atau program pengabdian masyarakat ke depannya.

\section{HASIL DAN PEMBAHASAN}

\section{Website untuk Penjualan Sirup Herbal secara Online}

Kondisi sebelum dilaksanakannya Program Kemitraan Masyarakat (PKM), mitra belum mempunyai website untuk penjualan produk sirup herbal. Padahal untuk meningkatkan jangkauan pemasaran sangat dibutuhkan peran digital marketing/online marketing, yang salah satunya adalah website. Dengan adanya website, produk sirup herbal akan lebih banyak dikenal secara nasional sehingga 


\section{INTEGRITAS : Jurnal Pengabdian}

Vol 5 No 2 Desember 2021

ISSN 2580 - 7978 (cetak) ISSN 2615 - 0794 (online)

akan meningkatkan jumlah calon konsumen yang berujung pada peningkatan omset dan profit atau keuntungan (Ngibad, Sembilu, \& Ula, 2021). Selain itu, peran website untuk produk sirup herbal akan membuat usaha tersebut menjadi lebih professional. Dalam program PKM ini, tim PKM membantu membuatkan website untuk mitra dan memberikan pelatihan kepada mitra terkait cara menggunakan dan mengelola website untuk penjualan sirup herbal. Gambar 2 menunjukkan bahwa pemateri sedang memberi pelatihan tentang pengelolan webisite kepada mitra. Hasil dari pelatihan pengelolaan website ini antara lain: tampilan website untuk penjualan sirup herbal (Gambar 3), tampilan website untuk menu "produk" (Gambar 4), tampilan website untuk menu "artikel" (Gambar 5), dan tampilan website untuk menu "kontak kami” (Gambar 6).

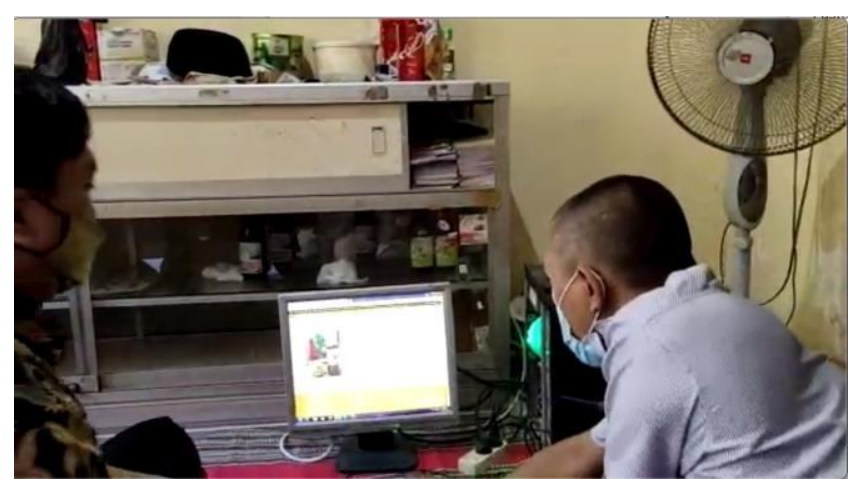

Gambar 2 Tim PKM sedang memberikan materi pelatihan website

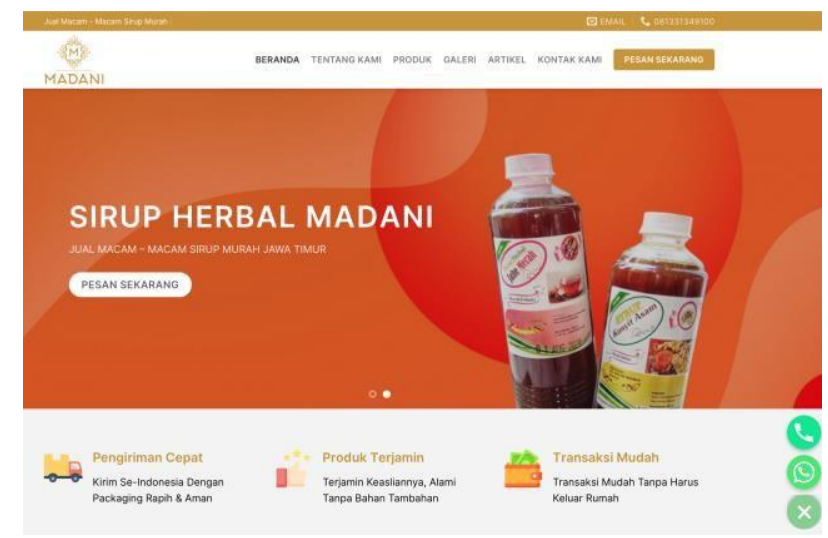

Gambar 3 Tampilan website untuk penjualan sirup herbal (http://www.sirupherbalmadani.com) 


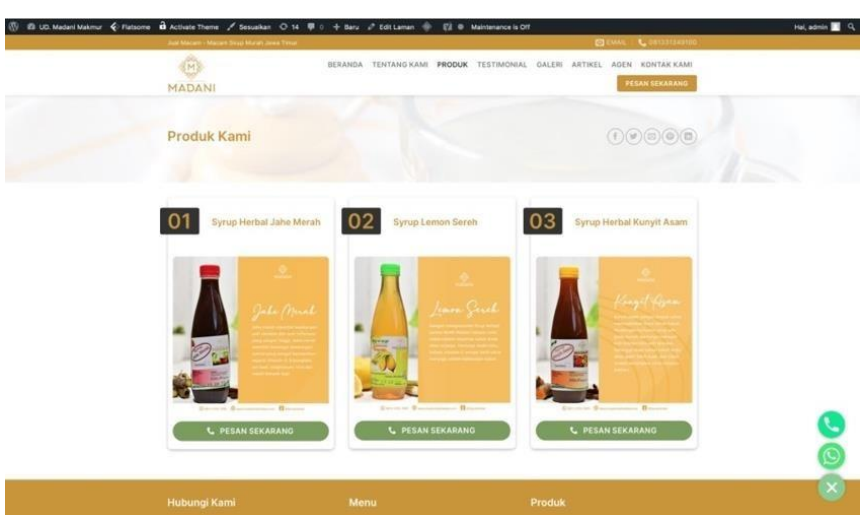

Gambar 4 Tampilan website untuk menu "produk"

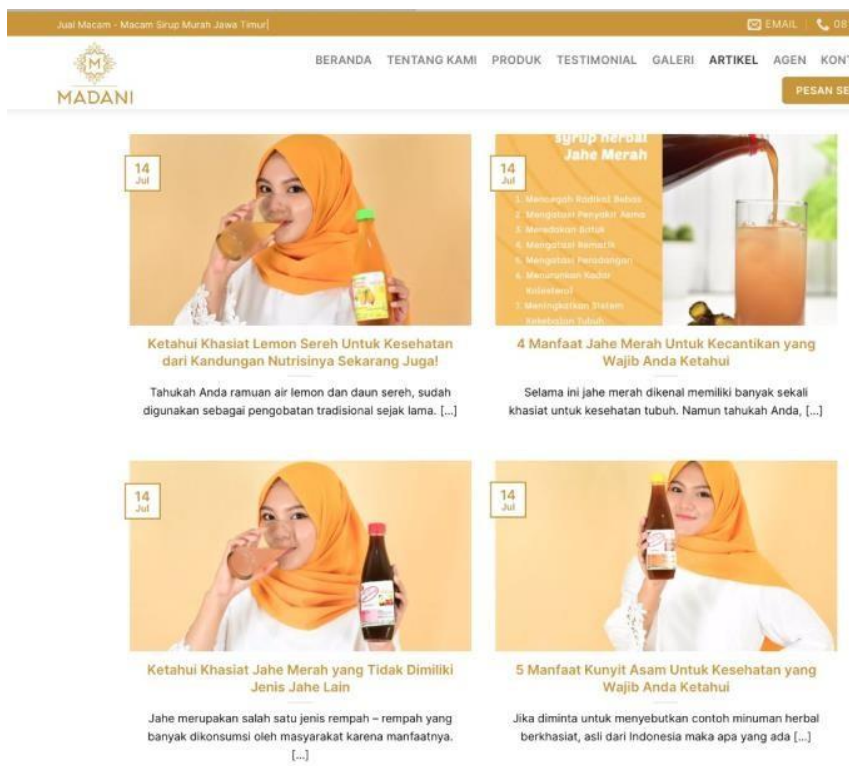

Gambar 5. Tampilan website untuk menu "artikel"

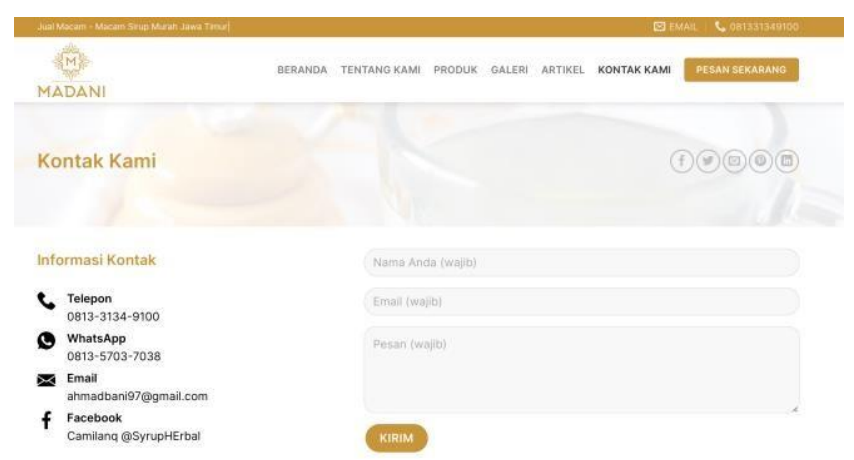

Gambar 6. Tampilan website untuk menu "kontak kami"

\section{Dashboard Google Adwords untuk Iklan Berbayar}

Penggunaan Google AdWords (Google Ads) di usaha mitra juga telah dilakukan agar dapat memperbesar mitra mendapatkan pelanggan baru. Google 


\section{INTEGRITAS : Jurnal Pengabdian}

Vol 5 No 2 Desember 2021

ISSN 2580 - 7978 (cetak) ISSN 2615-0794 (online)

Ads merupakan fitur iklan berbayar yang muncul di pencarian Google. Semakin tinggi posisi hasil pencarian di laman Google menggunakan paid search, tentu kemungkinan besar iklan akan dilihat lebih banyak orang sekaligus memperbesar peluang mendapatkan pelanggan (CNN Indonesia, 2020). Gambar 7 menunjukkan bahwa pemateri sedang memberi pelatihan Google Ads kepada mitra yang meliputi: dasar-dasar google express, cara membuat iklan adword express, cara setting adword express, cara setting pembayaran adword express, dan optimasi iklan adword express. Hasil dari pelatihan Google Ads adalah akun dashboard Google AdWords yang telah aktif iklannya sehingga mitra dapat menerapkan iklan berbayar dalam pemasaran online (Gambar 8).

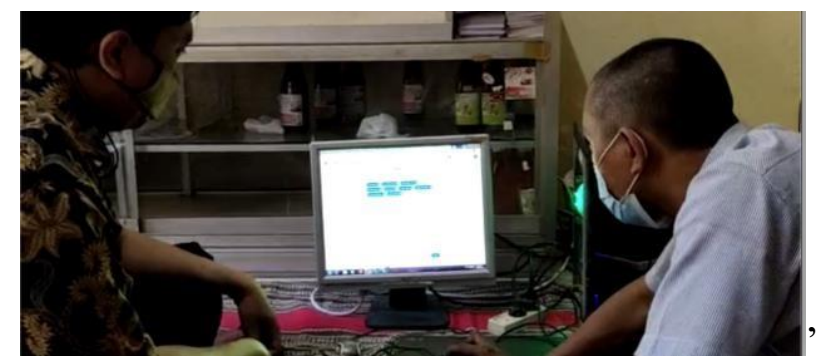

Gambar 7 Tim PKM sedang memberikan materi pelatihan Google Ads

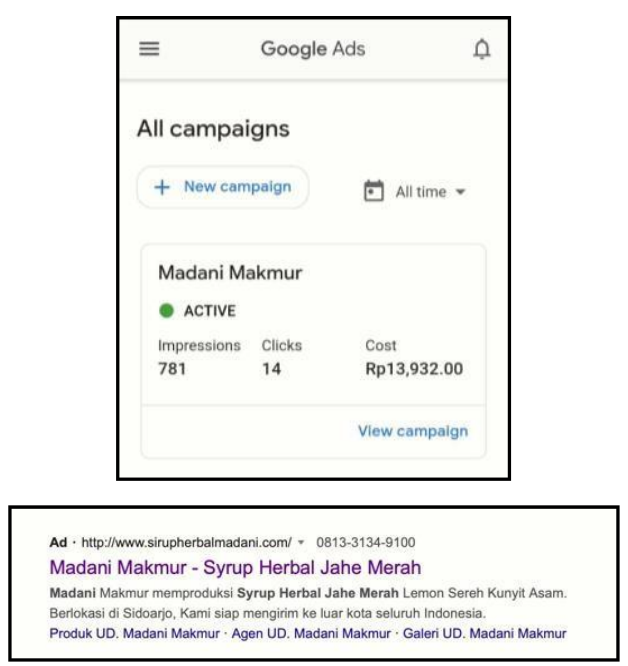

Gambar 8. Tampilan akun dashboard Google AdWords dan tampilan iklan berbayar di google

\section{Toko Online di Shopee}

Dalam rangka untuk memaksimalkan kegiatan pemasaran online mitra, tim PKM juga memberikan pelatihan dan pendampingan pembuatan serta pengelolaan 


\section{INTEGRITAS : Jurnal Pengabdian}

Vol 5 No 2 Desember 2021

ISSN 2580-7978 (cetak) ISSN 2615-0794 (online)

toko online di marketplace Shopee. Penerapan pemasaran online menggunakan marketplace Shopee di kelompok wanita "Mekar" mampu meningkatkan omset penjualan pengrajin keset kelompok wanita "Mekar" di bulan Agustus tahun 2020 hingga 50\% (Irianti, Susanti, Triswidrananta, \& Wijaya, 2021). Gambar 9 menunjukkan bahwa pemateri sedang memberi pelatihan pendampingan pembuatan serta pengelolaan toko online kepada mitra. Hasil dari kegiatan ini adalah toko online "Madani Makmur" di Shopee dapat di https://shopee.co.id/madani_makmur (Gambar 10).

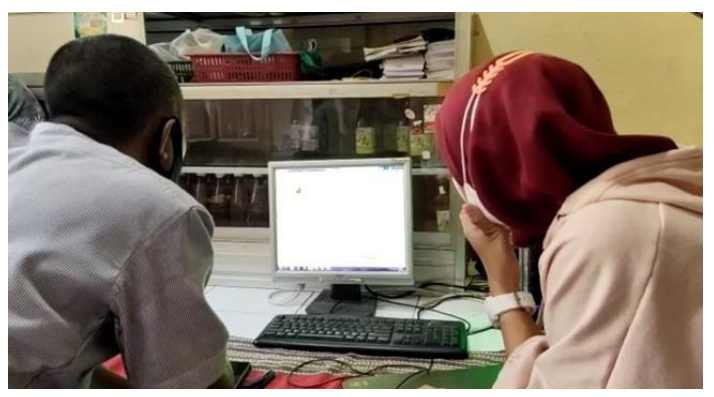

Gambar 9. Tim PKM sedang memberikan materi pelatihan Shopee

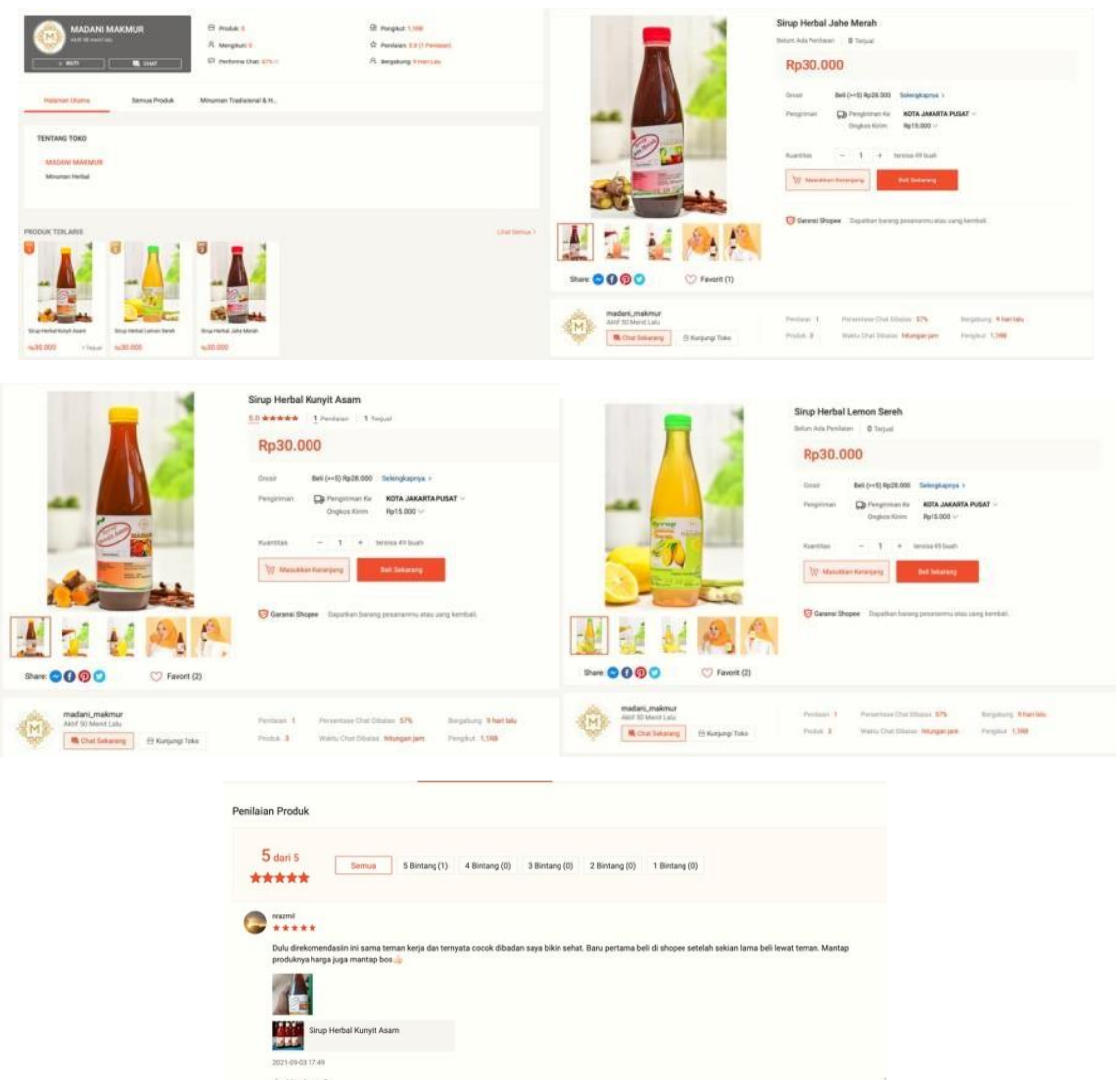

Gambar 10. Tampilan toko online "Madani Makmur" di Shopee 


\section{KESIMPULAN}

Pendampingan pemasaran online di UD. Madani Makmur Sidoarjo terlaksana dengan baik dan lancar. Setelah dilaksanakannya Program Kemitraan Masyarakat (PKM) ini, mitra mulai melakukan pemasaran mengggunakan media online, seperti: website, Google Ads dan marketplace Shopee.

\section{DAFTAR PUSTAKA}

CNN Indonesia. (2020). Panduan Menggunakan Google Ads dari A-Z untuk Pemula. Retrieved from https://www.cnnindonesia.com/teknologi/ 20200629172120-185-518739/panduan-menggunakan-google-ads-dari-az-untuk-pemula

Farell, G., Thamrin, T., \& Novid, I. (2019). Pelatihan Pemanfaatan Digital Marketing Dalam Pengembangan Pemasaran dan Kewirausahaan UKM pada Kota Sawahlunto. Suluah Bendang: Jurnal Ilmiah Pengabdian Kepada Masyarakat, 19(1), 42-47.

Irianti, N. P., Susanti, R. D. A., Triswidrananta, O. D., \& Wijaya, E. M. S. (2021). Peningkatan Omset Penjualan Kelompok Pengrajin Keset melalui Online Marketing. Abdimas: Jurnal Pengabdian Masyarakat Universitas Merdeka Malang, 6(1), 52-60.

Ngibad, K., Sembilu, N., \& Ula, K. (2021). Pelatihan dan Pendampingan dalam Pemasaran Produk Sirup Markisa Melalui Internet Marketing. AMALIAH: Jurnal Pengabdian Kepada MasyarakaT, 5(1), 32-39.

Nurfaizal, Y., \& Anwar, T. (2019). Manajemen Usaha dan Pelatihan Digital Marketing UMKM pada KUB Batik Pringmas Desa Papringan Banyumas. JPMB: Jurnal Pemberdayaan Masyarakat Berkarakter, 2(2), 146-154. 